ARTICLE

\title{
A general fruit acid chelation route for eco-friendly and ambient 3D printing of metals
}

Soo Young Cho (10) 1,7, Dong Hae Ho1,7, Yoon Young Choi ${ }^{1}$, Soomook Lim² ${ }^{2}$, Sungjoo Lee (i) ${ }^{3,4}$, Ji Won Suk ${ }^{2,4,5}$, Sae Byeok Jo ${ }^{6 \times} \&$ Jeong Ho Cho (iD ${ }^{1 \times}$

Recent advances in metal additive manufacturing (AM) have provided new opportunities for prompt designs of prototypes and facile personalization of products befitting the fourth industrial revolution. In this regard, its feasibility of becoming a green technology, which is not an inherent aspect of $\mathrm{AM}$, is gaining more interests. A particular interest in adapting and understanding of eco-friendly ingredients can set its important groundworks. Here, we demonstrate a water-based solid-phase binding agent suitable for binder jetting 3D printing of metals. Sodium salts of common fruit acid chelators form stable metal-chelate bridges between metal particles, enabling elaborate 3D printing of metals with improved strengths. Even further reductions in the porosity between the metal particles are possible through posttreatments. A compatibility of this chelation chemistry with variety of metals is also demonstrated. The proposed mechanism for metal 3D printing can open up new avenues for consumer-level personalized 3D printing of metals.

\footnotetext{
${ }^{1}$ Department of Chemical and Biomolecular Engineering, Yonsei University, Seoul 03722, Republic of Korea. ${ }^{2}$ School of Mechanical Engineering, Sungkyunkwan University, Suwon, Gyeonggi-do 16419, Republic of Korea. ${ }^{3}$ Department of Nano Engineering, Sungkyunkwan University, Suwon, Gyeonggi-do 16419, Republic of Korea. ${ }^{4}$ SKKU Advanced Institute of Nanotechnology (SAINT), Sungkyunkwan University (SKKU), Suwon, Gyeonggi-do 16419, Republic of Korea. ${ }^{5}$ Department of Smart Fab. Technology, Sungkyunkwan University, Suwon, Gyeonggi-do 16419, Republic of Korea. ${ }^{6}$ School of Chemical Engineering, Sungkyunkwan University, Suwon, Gyeonggi-do 16419, Republic of Korea. ${ }^{7}$ These authors contributed equally: Soo Young Cho, Dong Hae Ho.

凶email: eos0523@gmail.com; jhcho94@yonsei.ac.kr
} 
A dditive manufacturing (AM), also known as threedimensional (3D) printing, is one of the most important technologies in the fourth industrial revolution because it can enable the personalization of products and rapid prototyping. In an attempt to expand the boundaries of $\mathrm{AM}$, numerous researchers have focused on developing printable materials ${ }^{1-3}$ and corresponding techniques for $3 \mathrm{D}$ printing ${ }^{4-7}$. Consequently developed advanced and sophisticated printable materials and $3 \mathrm{D}$ printing techniques have accelerated the utilization of $A M$ in various industries, such as aerospace ${ }^{8,9}$, biomedicine ${ }^{10-12}$, and the food industry ${ }^{13,14}$. Research on metal AM that can facilitate its application to various industrial fields has also been actively conducted $^{15-18}$. However, unlike polymer AM, metal AM still has applicability only at the industrial and academic scales because of the demanding conditions of the printing environment, which hinder realization of consumer-level desktop applications. Selective laser melting and electron beam melting have been proposed as breakthrough technologies ${ }^{19-21}$, but printing processes requiring high-power energy sources, inert gas atmospheres, and high-temperature preheating have limited their application range $^{22}$.

Binder jetting metal 3D printing (BJM3DP) is a promising AM technique that selectively jets a liquid binding agent onto metal powder, which results in bond formation between particles ${ }^{23-25}$. The technological challenges for the commercial adaptation of BJM3DP still involve overcoming demanding conditions of metal AM processes including materials handling, post-treatments, and quality control. However, BJM3DP has particular advantages over other metal 3DPs, stemming from its high feasibility toward operationally low-cost, simple, and safe 3DP processes ${ }^{26}$. The ambient conditions of initial printing process ${ }^{27-30}$, as well as the possible use of commercially available ink cartridges constitute high accessibility to this technology than others, which can potentially facilitate consumer-level desktop applications. Moreover, as a groundwork for BJM3DP to become a more accessible green technology adequate for both industrial and personalized uses such as rapid prototyping, one of the important aspects to be explored is adapting and understanding of environmentally friendly ingredients including binder materials. The two most commonly used hazardous binding agents, 2-butoxyethanolbased solution and 2-pyrrolidone-based solution, have been specifically considered to be responsible for such issues ${ }^{31,32}$. Additionally, the recently developed metal-organic dispersion ink composed of cupric formate and octylamine has also been found to have an adverse environmental impact ${ }^{33,34}$. In the field of ceramic BJ3DPs, especially for biomedical applications, there already are various investigations regarding the use of nonhazardous binder materials such as green-solvent-soluble polymers, maltodextrin, sugar, and corn starch ${ }^{35-37}$. However, only a few candidates for metal BJ3DP have been explored so far, and the reported characteristics of printed objects such as the porosity and mechanical strengths are far below the ones based on the aforementioned common binder materials ${ }^{38}$. Therefore, it is now imperative to broaden the technological horizon thorough developing new green binding agents for metals that can be ecofriendly as well as non-hazardous ${ }^{24,39-41}$, with prospects of simultaneously achieving the desired properties of printed objects.

Here, we introduce a binding mechanism for BJ3MDP that is based on the use of a chelator composed of salts of naturally available fruit acids as an eco-friendly binding agent. Metalchelate bridges between metal particles are successfully formed via ink-jetting of water onto a powder composed of a uniform mixture of the metal particles and chelator. This metal-organic complexing mechanism is thoroughly analyzed by Fourier transform infrared (FT-IR) spectroscopy, X-ray photoelectron spectroscopy (XPS), and scanning electron microscopy (SEM). Then, compression tests are performed on the metal 3D-printed object to confirm the dependence of its mechanical strength on the type of chelator. Subsequently, the mechanical strength is further improved by post-treatments as well as optimizing the distribution of particle sizes and compositions. Finally, objects of various shapes are printed using various metals, which demonstrates that the proposed chelator-assisted BJM3DP technique is not only useful for the realization of complex and sophisticated architectures but also applicable to a wide range of metal powders. The environmentally friendly chelator presented herein is expected to promote greener metal 3D printers adequate for both industrial and consumer-level scale applications.

\section{Results}

Eco-friendly BJM3DP. Figure 1a shows the 3D scheme of the BJM3DP system, which has four main components: an inkjet cartridge, powder gantry boxes, a roller, and $x$ - and $y$-axes stages. Prior to the $3 \mathrm{D}$ printing process, the powder and inkjet cartridge were prepared as follows (see Supplementary Fig. 1 for photographic images of each component). First, the metal powder was mixed with the chelator. Here, the nozzle clogging issue from the precipitation of binding agents inside inkjet cartridge was avoided since the chelator functions as a solid-phase binding agent premixed with metal particles, which also is one of the commonly adopted approaches in biomedical fields ${ }^{35-37,42}$. Next, two gantry boxes were filled with the mixture of the metal powder and chelator; for the purpose of this work, Al powder was utilized. Each of these gantry boxes has a different purpose. One is the builder gantry box in which objects are 3D-printed, and the other is the feeder gantry box that stores and supplies the powder to the builder gantry box. Then, the inkjet cartridge was filled with deionized (DI) water, which activated the chelation reaction. After the preparation process, the printing cycle was initiated through the deposition of a powder layer on top of the builder gantry box. During the printing process, the builder platform moved one step downward to provide space for one powder layer and the feeder platform simultaneously moved one step upward to push up the powder. Then, the roller module positioned at the feeder gantry box moved toward the builder gantry box to supply powder and flatten powder protruding on top of the latter box, as shown in Fig. 1b. Once a powder layer was deposited, the module returned to its original position. Subsequently, DI water was jetted from the inkjet cartridge onto the powder layer deposited on top of the builder gantry box at programmed positions (Fig. 1c). This cyclic process was repeated until the uppermost layer of the designed $3 \mathrm{D}$ object was deposited. Upon completion of the printing cycle, the $3 \mathrm{D}$-printed object was removed from the pile of metal powder and the unchelated powder was subsequently removed through air blowing. Photographic images of the overall metal 3D printing process are shown in Supplementary Fig. 2. As a safety disclaimer, the Al powder is classified with ST3 explosive ratings, which can pose a potential danger for $\mathrm{Al}$ powder-based systems. Furthermore, a plausible reaction between water and $\mathrm{Al}$ could also generate combustible hydrogen during the process, thus a proper ventilation and an equipment of hydrogen detectors are required for the safe operation. In our experimental system (capable of jetting $250 \mathrm{ml}$ of water over $6 \mathrm{~h}$ ), $193 \mathrm{ppm} /$ hour of hydrogen generation was observed, which would indeed pose danger over $200 \mathrm{~h}$ of continuous printing in a completely closed system by reaching the lower explosive limit of the hydrogen $(41,000 \mathrm{ppm})^{43}$.

As binding agents, nature-based chelators, which are crucial to ensure eco-friendliness of metal 3D printing, were used. Unlike polymer binding agents, which are hazardous, the chelators 
a

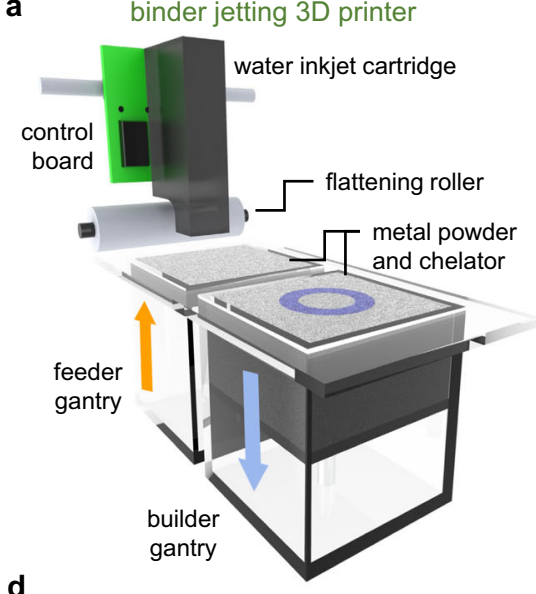<smiles>O=C(O)CC(O)(CC(=O)O)C(=O)O</smiles><smiles>O=C(CC(O)(CC(=O)O[Na])C(=O)O[Na])O[18O]</smiles>

b

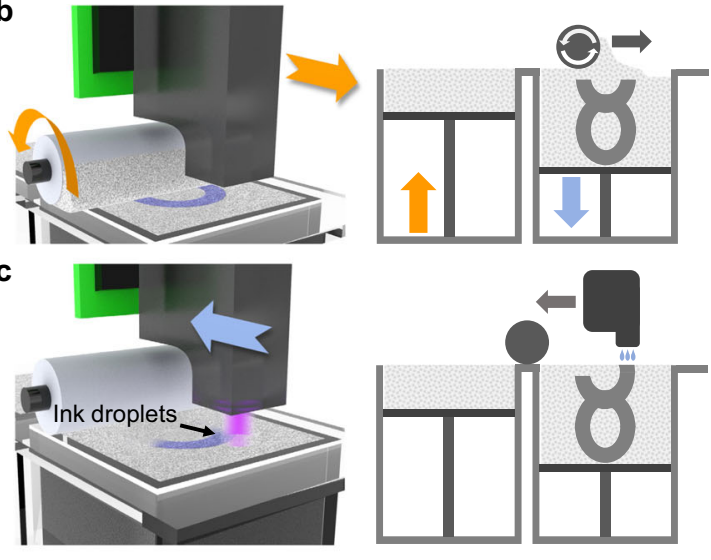

e

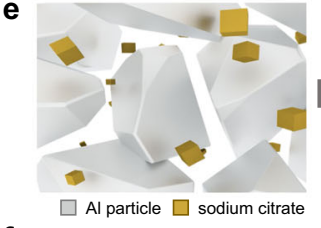

$\mathbf{f}$

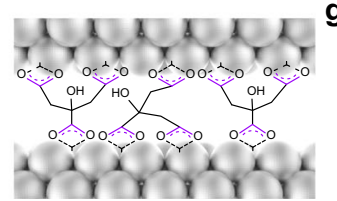

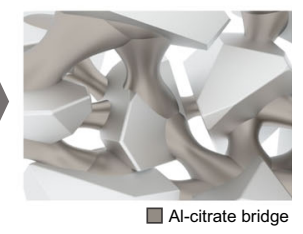

g

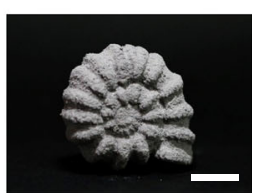

Fig. 1 Eco-friendly BJM3DP. a Schematic illustration of BJM3DP system. b Powder layer deposition on builder gantry box. c Programmed water ink-jetting onto powder layer. $\mathbf{d}$ Chemical structures of naturally available eco-friendly fruit acid (top) and its sodium salt (bottom). e Schematic description of asprepared mixture of metal powder and chelator (left) and metal-chelate bridge formation after metal chelation (right). f Chemical structure of metalchelate bridges on metal particle surface. $\mathbf{g}$ Photographic image of 3D-printed ammonite-shell-shaped object (scale bar: $10 \mathrm{~mm}$ ).

utilized here are food-grade organic materials because they are salts of nature-based fruit acids (e.g., of fruits such as lemons, cherries, and grapes $)^{44}$. For example, citric acid derived from citrus fruits has three carboxyl groups, and it transforms into sodium citrate upon replacement of the hydrogens in these groups with sodium ions through a salt-formation reaction (Fig. 1d $)^{45}$. Here, the carboxyl group of sodium citrate plays an important role in the metal chelation reaction. Upon wetting of the uniform mixture of the metal powder and chelator (Fig. 1e), metal chelation occurs on the surface of the metal particles, which induces the formation of metal-chelate bridges between the particles. Figure if and Supplementary Fig. 3 show the chemical structure of metal-chelate bridges formed on metal particle surface and the change in the microstructure of $\mathrm{Al}$ powder. Successful chelation imparts structural integrity to the 3D-printed object and its architecture is consequently maintained, as a result of which the object has a precise and sophisticated shape, as shown in Fig. 1g.

Formation of metal-chelate bridges between metal particles. Figure $2 \mathrm{a}$ shows the mechanism of chelate complex formation between $\mathrm{Al}$ particles and the underlying chemical reaction. When water droplets are jetted onto $\mathrm{Al}$ powder, water permeates between the particles and gradually dissolves the chelator. Then, the ionized chelator solution preferentially attacks intrinsic defects in the $\mathrm{Al}$ particles, consequently producing Al-chelate compounds, which results in the bridging of the $\mathrm{Al}$ particles. Figure $2 \mathrm{~b}$ shows FT-IR spectra of $\mathrm{Al}$ objects printed using the following proposed chelators: sodium salts of citrate (NaCit), tartrate (NaTar), succinate (NaSuc), and ascorbate (NaAsc). These four chelators have three, two, two, and one coordinate donor sites, respectively, and the difference in the number of coordination sites affects the formation of metal-chelate bridges. In the spectra of the carboxyl-based chelators (NaCit, NaTar, and NaSuc), two major bands, which originate from the asymmetric stretching vibration $\left(v_{\text {as }}\left(\mathrm{COO}^{-}\right)\right)$ and symmetric stretching vibration $\left(v_{\mathrm{s}}\left(\mathrm{COO}^{-}\right)\right)$of the carboxylate group $\left(\mathrm{COO}^{-}\right)$, are present in the frequency ranges of $1540-1720 \mathrm{~cm}^{-1}$ and $1320-1470 \mathrm{~cm}^{-1}$, respectively ${ }^{46}$. In the spectra of $\mathrm{NaCit}, v_{\mathrm{as}}\left(\mathrm{COO}^{-}\right)$at $1592 \mathrm{~cm}^{-1}$ and $v_{\mathrm{s}}\left(\mathrm{COO}^{-}\right)$at $1393 \mathrm{~cm}^{-1}$ are blue-shifted by $4 \mathrm{~cm}^{-1}$ and red-shifted by $11 \mathrm{~cm}^{-1}$, respectively, after chelation. The increase in the molecular mass due to the chelation of the carboxylate group and $\mathrm{Al}$ causes a change in the vibration frequency, which results in a band shift ${ }^{47}$. The peak shifts of $v_{\text {as }}\left(\mathrm{COO}^{-}\right)$and $v_{\mathrm{s}}\left(\mathrm{COO}^{-}\right)$thereby indicate the formation of the chelate complex on the Al particle surface (the FT-IR spectrum of pristine $\mathrm{Al}$ powder in the same frequency range is shown in Supplementary Fig. 4). The separation of peaks $\left(\Delta v=v_{\text {as }}-v_{\mathrm{s}}\right)$ was further analyzed to identify the difference in the types of coordination between $\mathrm{Al}$ and the carboxyl-based chelators $^{48}$. Because NaCit, NaTar, and NaSuc chelated with $\mathrm{Al}$ have a lower value of $\Delta v\left(\mathrm{COO}^{-}\right)$than do the chelators themselves (Supplementary Table 1), these chelators coordinate with $\mathrm{Al}$ in the bidentate chelating form, which enables a single metal atom to have two bonds with a carboxylate group, as illustrated in the left panel of Fig. 2b. Unlike with these carboxylate-based chelators, $\mathrm{NaAsc}$ forms only a single bond with the $\mathrm{Al}$ atom, as indicated by the non-split $v_{\mathrm{C}=\mathrm{O}}$, the band broadening of $v_{\mathrm{C}-\mathrm{O}}$, and the decreased intensity of the hydroxyl group after chelation ${ }^{49}$.

The XPS spectra of chelated Al provide information about the extents of chelate complex formation when the different chelators are used. The left panel of Fig. 2c and Supplementary Fig. 5 show the $\mathrm{Al} 2 p$ and $\mathrm{O} 1 s$ spectra of the chelated and pristine $\mathrm{Al}$ powders, respectively. The deconvoluted $\mathrm{Al} 2 \mathrm{p}$ 
a

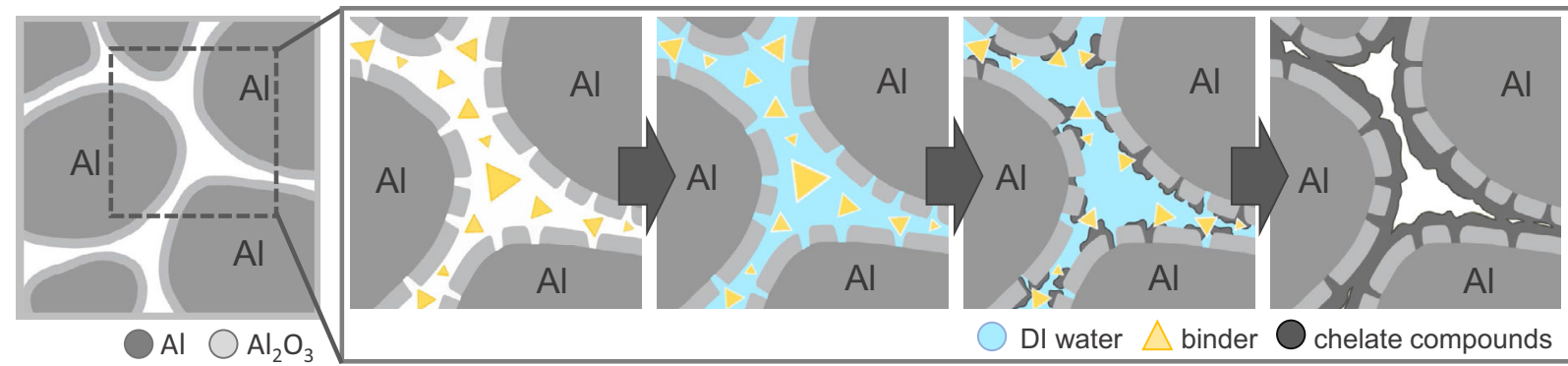

b

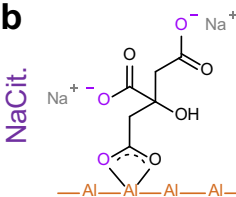

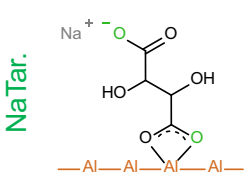
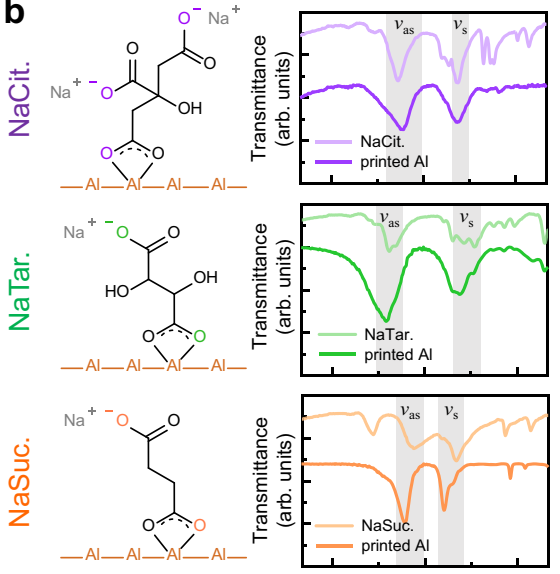<smiles>O=C(O)COC(=O)OC1=C(O)C(=O)OC1C(O)CO</smiles>

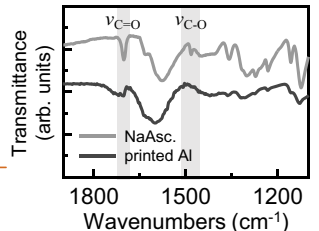

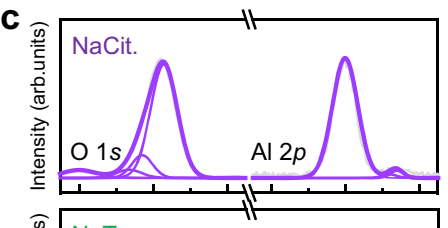
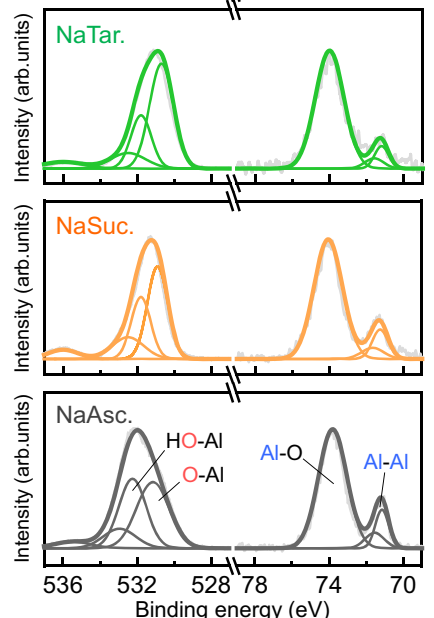
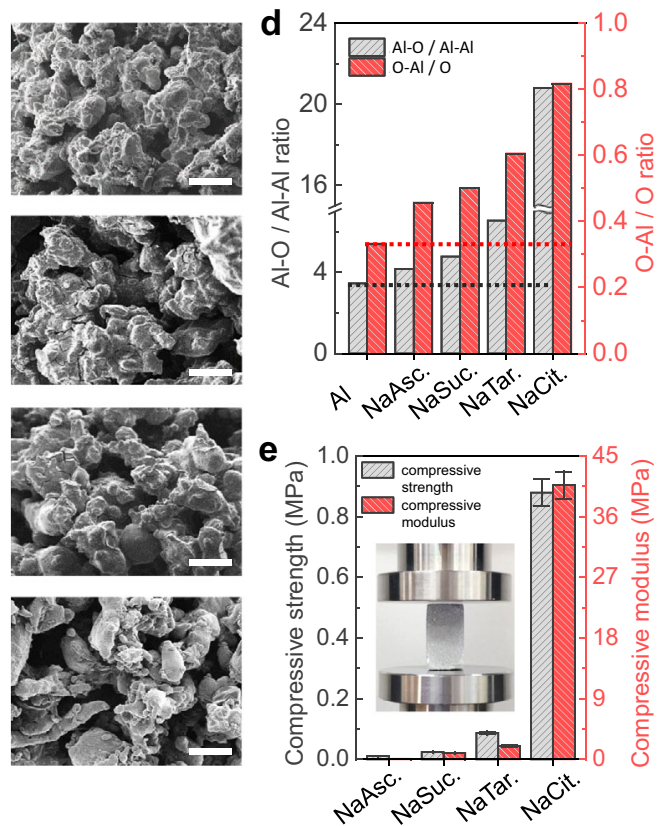

Fig. 2 Formation of metal-chelate bridges between metal particles. a Schematic illustration of mechanism of metal chelation on metal particle surface. b Chemical structures of chelators and their coordination with metal particle surface (left) and FT-IR analysis with identified vibration peaks (right). c Deconvoluted XPS peaks (left) and cross-sectional SEM images of chelated metal particle surface (right) (scale bar: $100 \mu \mathrm{m}$ ). d Al-O/AI-Al atomic ratio (integrated areas of peaks in $\mathrm{Al} 2 p$ spectra) and O-Al/O atomic ratio (integrated areas of peaks in $\mathrm{O} 1 \mathrm{~s}$ spectra) for various chelators. e Compressive strength and modulus of objects 3D-printed by BJM3DP using various chelators. Data are presented as mean values \pm standard deviations. The inset shows a photographic image of compression testing of the 3D-printed object.

spectra have three distinct components: $\mathrm{Al} 2 p_{3 / 2}(71.6 \mathrm{eV}), \mathrm{Al}$ $2 p_{1 / 2}(72.0 \mathrm{eV})$, and $\mathrm{Al}-\mathrm{O}(74.2 \mathrm{eV})$. The Al-O peak originates from the oxides and hydroxides formed on the Al surface ${ }^{50}$. As depicted in Fig. 2d, the four types of chelated Al show a larger $\mathrm{Al}-\mathrm{O} / \mathrm{Al}-\mathrm{Al}$ atomic ratio than the pristine $\mathrm{Al}$ particles. Furthermore, the atomic ratio increases as the number of coordination bonds increases. These results indicate that the chelators play a pivotal role in $\mathrm{Al}-\mathrm{O}$ formation, and greater the number of coordination bonds, higher is the thickness of the $\mathrm{Al}^{-}$ $\mathrm{O}$ layers formed on the $\mathrm{Al}$ particle surface, as observed in the SEM images (right panel of Fig. 2c). This tendency of formation of a thicker Al-O layer is also confirmed from the $\mathrm{O} 1 s$ spectra. The $\mathrm{O} 1 s$ peak has three components, which correspond to O$\mathrm{Al}, \mathrm{HO}-\mathrm{Al}$, and the chemisorbed water and are positioned at $530.7,531.8$, and $532.4 \mathrm{eV}$, respectively ${ }^{51}$. As can be seen from the plot in Fig. 2d, the relative amount of $\mathrm{O}-\mathrm{Al}$ increases as the number of coordination bonds increases; this trend reveals that a chelator with more coordination sites is favorable for the formation of the Al-chelate complex. The promoted chelation results in stronger bonding between the metal particles, and therefore, increases the mechanical strength of the 3D-printed objects (Fig. 2e). The object printed using $\mathrm{NaCit}$ has the highest compressive strength $(0.88 \mathrm{MPa})$ and compressive modulus $(40.66 \mathrm{MPa})$. The improved mechanical properties of $3 \mathrm{D}$ - printed object based on $\mathrm{NaCit}$ than other chelators in our study can be explained by the fact that coordinate donor sites contribute to the strength of the 3D-printed object. Changes in the atomic ratio and mechanical properties with the type of chelator because of the difference in the number of coordination groups are depicted in Supplementary Fig. 6. $\mathrm{NaCl}$ was subsequently added to release more metal ions from the intrinsic defects in the $\mathrm{Al}$ particles and increase the binding strength of the printed object. Upon the addition of $\mathrm{NaCl}$, the chloride ions attacked the $\mathrm{Al}$ defects to form $\mathrm{Al}$ ions, which, in turn, promoted chelation on the surface of the metal particles in an aqueous environment (Supplementary Fig. 7) ${ }^{52}$. The enhancement of chelation through $\mathrm{NaCl}$ addition was also confirmed by SEM, FT-IR spectroscopy, and XPS (Supplementary Figs. 8 and 9), all of which revealed numerous metal-chelate bridges. The increase in the density of metal-chelate bridges, in turn, led to an increase in the compressive modulus to $68.36 \mathrm{MPa}$; this is a 1.7 -fold increase compared to that of the 3D-printed object not treated with the $\mathrm{NaCl}$ additive, as shown in Supplementary Fig. 10. Further enhancements in the mechanical strengths can very well be acquired through posttreatments as well as optimizing the distribution of particle sizes and compositions (Supplementary Fig. 11), which are described in the following section. 


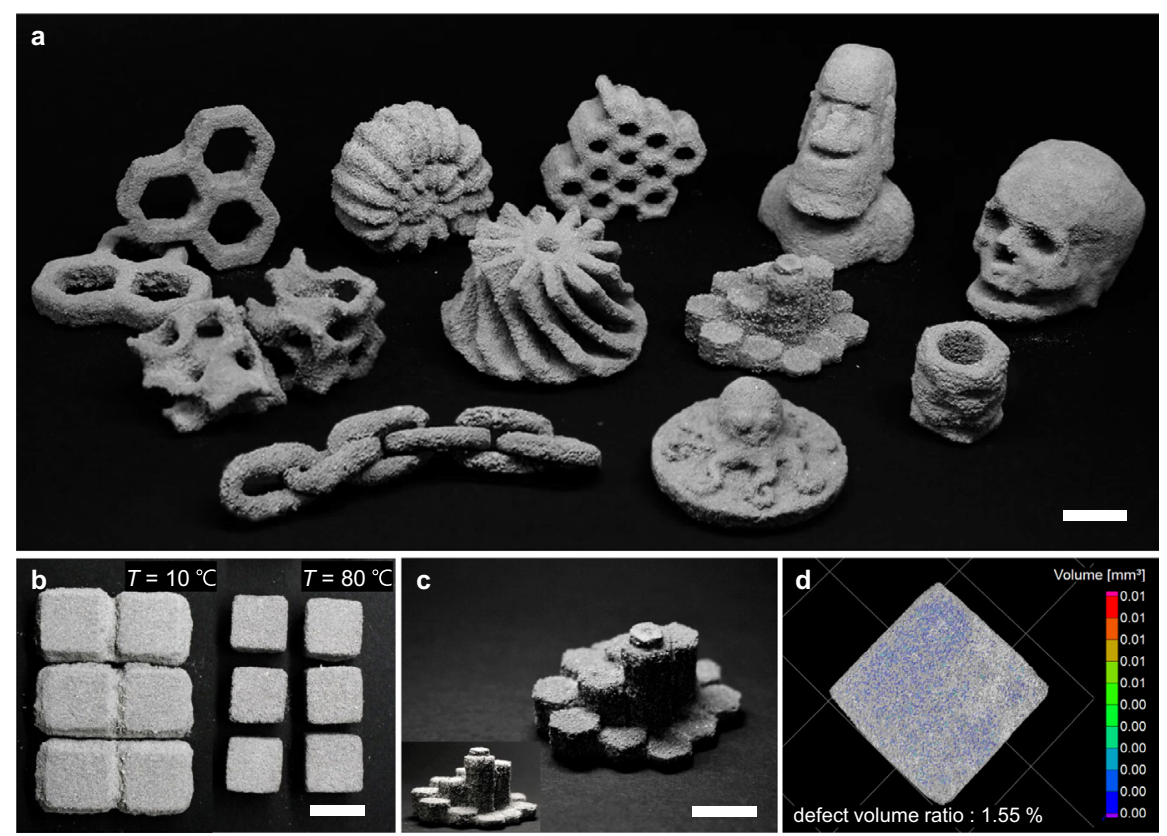

Fig. 3 Various objects 3D-printed using NaCit chelator. Photographic images of a 3D-printed Al objects having various shapes. $\mathbf{b}$ Demonstration of the minimization process for bleeding effects by using different initial printing conditions. The temperature of builder was gradually increased from 10 to $80{ }^{\circ} \mathrm{C}$. c Photographic images of representative 3D-printed objects, which depict their high dimensional accuracy. $\mathbf{d}$ Rendered image and defect volume ratio from $\mu \mathrm{CT}$ analyses for green body based on metal particles with a bimodal powder distribution based on 10 and $75 \mu \mathrm{m}$ metal particles. The scale bar on the images is $10 \mathrm{~mm}$. Three-dimensional model data for the ammonite shell (thing: 1611970), moai statue (thing: 3905999), octopus (thing: 159217), gyroid cube (thing: 757884), skull (thing: 11953), hexagon stair sculpture (thing: 46966), and faceted cup (thing: 414252) were acquired from the open-source website www.thingverse.com. Other 3D models were designed by the authors using Fusion 360 software.

Applicability of NaCit chelator for 3DP of metal objects. To demonstrate the capability of our developed BJM3DP system in producing elaborate objects, we designed and 3D-printed various 3D structures, as shown in Fig. 3a and Supplementary Fig. 12. For the industrial applications of BJM3DPs, various aspects should be taken into accounts, including the bleeding effect, stair-stepping effect, liquid-powder imbibition effect, as well as sensitive processing parameters such as powder size distribution, powder layer consistency, and layer shifting during drying ${ }^{53,54}$. Those aspects critically determine the resolution and mechanical strengths of 3DP objects. As a first step, testing and securing the microstructural integrity of 3D printed objects were considered in the fabrication of objects with sophisticated geometries, such as a gyroid cell, an impeller, an ammonite shell, and a skull. In addition, the bleeding issue-a phenomenon in which the binding agent solution adversely flows out of the printed object due to the capillary forces-was addressed to ensure high printing quality ${ }^{24}$. The use of water as a jetting fluid for the initial printing process as well as a for the posttreatment enabled a partial mitigation of this issue: it has higher vapor pressure than conventional binding agent solutions, because of which it evaporates faster and therefore reduces the solution from flowing out of the prescribed structure, especially at elevated printing temperatures used in our study (Fig. 3b and Supplementary Fig. 14). A post-treatment step of the humidification then ensures the completion of the remnant chelation reaction between metal particles without causing adversary bleeding (discussed in the following section). Consequently, the dimensional accuracy of the 3D-printed objects as shown in Fig. $3 \mathrm{c}$ can be acquired. Figure 3d and Supplementary Fig. 15 show the rendered images and extracted void ratios of the printed object from computed 3D X-ray microtomography $(3 \mathrm{D} \mu \mathrm{CT})$ analyses. A good packing density (defect volume ratio of $4.92 \%$ ) of the green body based on coarse $\mathrm{Al}$ powder $(<355 \mu \mathrm{m})$ by itself not only enables the 3D object to retain its shape but also promotes the solidification of the structure during the subsequent post-treatment process, thereby providing structural integrity. On the other hand, to illustrate prospects of further enhancing the mechanical strengths of BJM3DP objects, we optimized the distribution of the powder sizes and compositions ${ }^{55,56}$. In regards to overcoming the low intrinsic porosity of BJM3DP objects (30-60\% in general) and reducing microscopic void ratios, we used a bimodal powder distribution based on 10 and $75 \mu \mathrm{m}$ metal particles (Supplementary Fig. 16). The improved packing of the metal powders from the filling of interstitial voids with fine particles (Supplementary Figs. 15 and 17) thus led defect volume ratios to be critically reduced ( 1.55 and $0.30 \%$ for green and sintered body, respectively). As a result, greatly improved mechanical strengths and compressive modulus of green body up to $6.06 \mathrm{MPa}$ and 218.43 MPa, respectively, were obtained. After completing thermal debinding and sintering processes for printed green bodies (Fig. 4a), the values could further be improved to $29.59 \mathrm{MPa}$ and $1.49 \mathrm{GPa}$, respectively (Fig. 4b). These results are indeed much superior than the values acquired in previous reports on green-solvent-soluble binders, and are even comparable to the $\mathrm{Al}$ (or Al alloy)-based metal objects printed by other much more sophisticated 3DP methods based on high powered lasers (Fig. $4 \mathrm{c}$ and Supplementary Fig. 18).

Post-treatment process and several 3D-printable metals. The post-treatment process performed for strength improvement in the standard metal BJM3DP technique can also be applied to the chelation-based metal 3D printing technique proposed herein. The post-treatment consists of a two-step process: humidification followed by thermal sintering. First, the unreacted chelator between particles was fully reacted through humidification (see Supplementary Fig. 19 for the SEM image of the humidified 3Dprinted object). Since we chose to use a marginal water droplet size $(33 \mathrm{pL})$ at elevated evaporation conditions (builder/nozzle temperature of $70^{\circ} \mathrm{C}$ ) to minimize the bleeding effect (see 
a

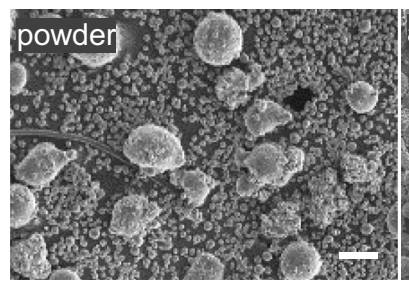

b

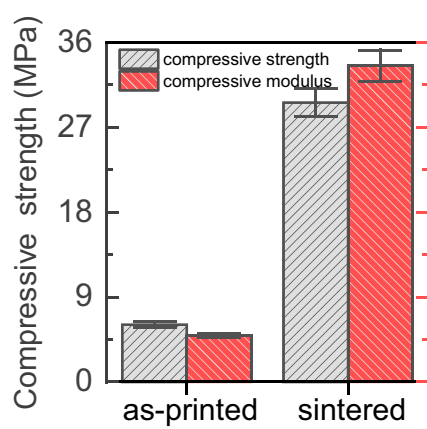

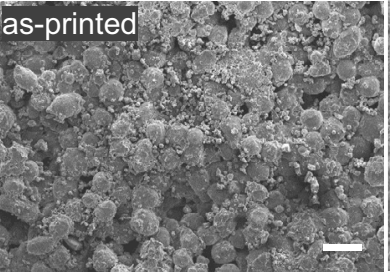

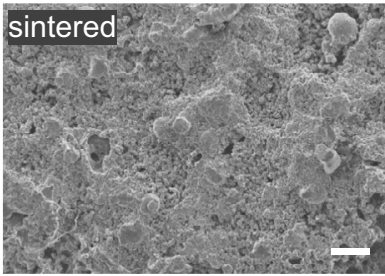

C

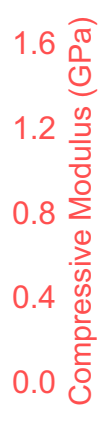

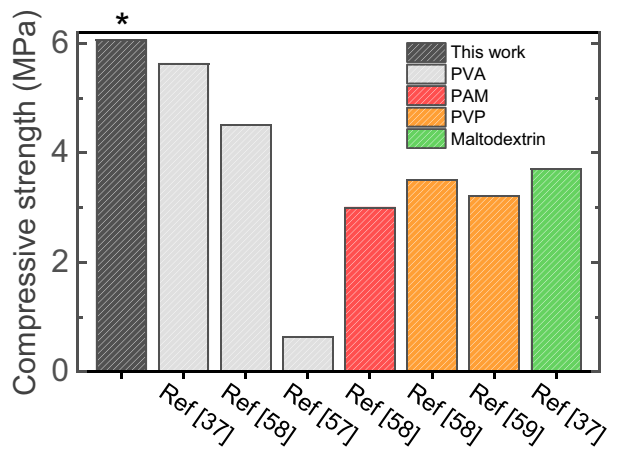

d

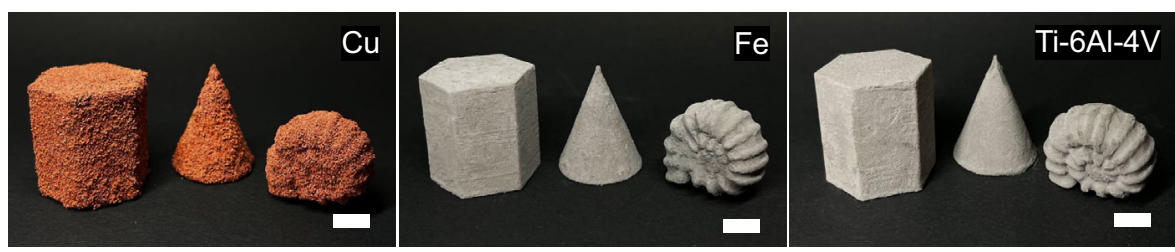

e
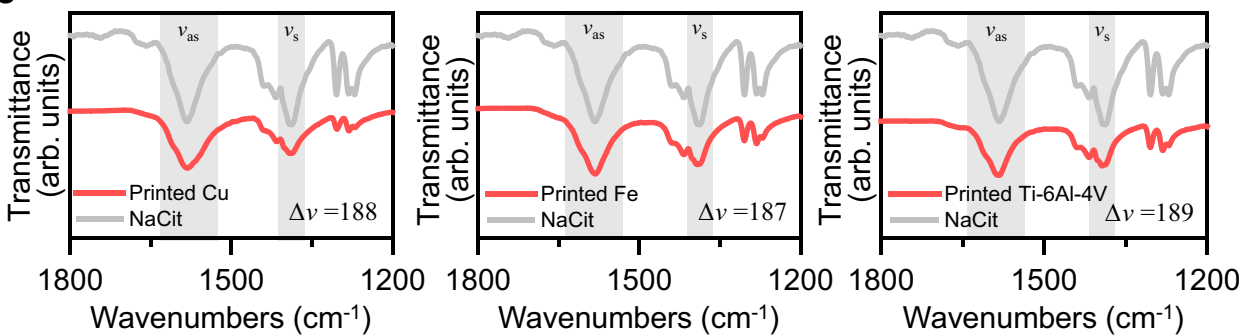

Fig. 4 Post-treatment process and several 3D-printable metals. a Cross-sectional SEM images of powder (left), as-printed 3D object (middle) and

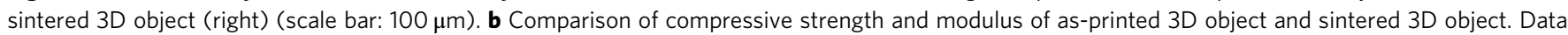
are presented as mean values \pm standard deviations. c The recent technological progress in BJM3DP techniques, with respect to the mechanical strengths of printed green bodies based on various binder materials. d Photographic images of objects 3D-printed using Cu (left), Fe (middle), and Ti-6Al-4 V alloy (right) (scale bar: $10 \mathrm{~mm}$ ). e The FTIR spectra and corresponding peak separation $\left(\Delta \nu\left(\mathrm{COO}^{-}\right)\right.$) of $3 \mathrm{D}$ printed $\mathrm{Cu}, \mathrm{Fe}$, and Ti-6 Al-4V objects compared to the one for pure $\mathrm{NaCit}$.

Supplementary Fig. 14 for details), an additional step of the humidification can complete the reaction between surplus chelator and particles, and indeed boosts the strengths of the printed objects without sacrificing the printing resolution. Subsequent thermal debinding and sintering (see Supplementary Fig. 20 for detailed procedure) caused solid-state diffusion of metal particles, which led to a decrease in the interparticle porosity, as shown in Supplementary Fig. 21. In other words, the metal particles came into closer contact with their neighboring particles, as shown in Fig. 4a. Consequently, the compressive strength and compressive modulus of the thermally sintered 3D-printed objects are greatly improved, compared to those in the as-printed state (Fig. 4b).

These strategies are expected to contribute to improvement in the mechanical properties of printed objects through minimization of the void ratios and porosity in final products. Figure $4 \mathrm{~d}$ shows objects $3 \mathrm{D}$-printed using copper $(\mathrm{Cu})$, iron $(\mathrm{Fe})$, and a titanium-aluminum-vanadium alloy $(\mathrm{Ti}-6 \mathrm{Al}-4 \mathrm{~V})$. The printed objects showed structural integrity that cannot be acquired through jetting of water alone without our solid-phase binder mixed with metal particles (Supplementary Fig. 22). Furthermore, FT-IR spectra of all printed metal objects exhibit noticeable shifts in $\Delta v\left(\mathrm{COO}^{-}\right)\left(188 \mathrm{~cm}^{-1}\right.$ for $\mathrm{Cu}, 187 \mathrm{~cm}^{-1}$ for $\mathrm{Fe}$ and $189 \mathrm{~cm}^{-1}$ for $\mathrm{Ti}-6 \mathrm{Al}-4 \mathrm{~V})$ compared to pure $\mathrm{NaCit}\left(198 \mathrm{~cm}^{-1}\right)$, which agree with the trend we observed in Al-based printed objects (Fig. 4e). Changes in ionic compositions between pure and BJM3DP-printed metals were also observed, wherein $\mathrm{Cu}^{2+}, \mathrm{Fe}^{3+}$, and $\mathrm{Al}^{3+}$ can preferentially chelate with $\mathrm{COO}^{-}$of citrate ions (Supplementary Fig. 23). These results demonstrate that our chelator is feasible for forming chelation bridges between metal particles of other metals, and thus can be applied as a binder for BJM3DPs of various metals and alloys than just $\mathrm{Al}$ alone.

\section{Discussion}

An eco-friendly chelator-based binding mechanism for BJM3DP was proposed and the feasibility of achieving an effective 3D printing system was demonstrated in this study. In the field of BJM3DPs, a few candidates for green-solvent-soluble binders have been reported so far, such as polyvinyl alcohol (PVA) ${ }^{37,42,57}$, polyacryl amide 
$(\mathrm{PAM})^{58}$, polyvinyl pyrrolidone (PVP) ${ }^{59}$, and maltodextrin ${ }^{37}$, some of which were adopted from successful demonstrations in the field of ceramic BJ3DPs for biomedical applications $s^{58}$. However, the mechanical properties of the printed metal objects based on them, even with highly tough $\mathrm{Ti}-6 \mathrm{Al}-4 \mathrm{~V}$ alloy, were mostly rather less competitive for broad applications compared to the ones based on common binder materials developed without considerations for ecofriendliness. Among them, dextrin, a liquid-based binder, has shown promises that can provide meaningful mechanical properties to the printed green bodies of Al/alumina (Fig. 4c). As a solid-phase binder, PVA has been adopted but the mechanical properties achieved was abysmal ${ }^{57}$ contrary to previous demonstrations of reasonable binding properties in ceramic (hydroxyapatite) ${ }^{37}$ BJ3DPs. In comparison, results in this work demonstrated that the citric acid, as an another solid-phase green binder that only requires the jetting of pure water for the structural formation, can endorse prospects of simultaneously achieving desired mechanical properties of printed objects as well as the eco-friendly and facile printing processing. By using citric acids as binders, the structural integrity of the 3Dprinted objects can be achieved through the efficient formation of metal-chelate bridges between metal particles. A combination of optimized powder size distribution and the efficient binding properties of citric acid, therefore, enabled high packing densities for both green and sintered body of printed $\mathrm{Al}(1.55$ and $0.30 \%$ defect volume ratios, respectively). The optimized packing then led to the achieved good mechanical strengths ( $\sim 30 \mathrm{MPa}$ in compressive strength) for $\mathrm{Al}$ objects, which were comparable to or even higher than the ones printed by other sophisticated metal 3DPs based on high powered lasers (Supplementary Fig. 18). The porosity of the green body, on the other hand, still has a room for enhancements, even though the value $(41 \%)$ itself is well within the previous reports $(30-60 \%)^{60-62}$. Furthermore, the resolution of the $3 \mathrm{D}$ printed objects, which is another important aspect along with mechanical strengths, can be enhanced by controlling the evaporation of jetted water. The inevitable liquid-powder imbibition could be reduced by elevating the builder temperature near evaporation point $\left(70^{\circ} \mathrm{C}\right)$ of water, of which the plausible insufficiency in the metal bridging from the fast evaporation was compensated by using an additional step of the humification that completes the remnant chelation process between metal particles and citrates (Supplementary Fig. 19). The whole printing process based on citric-acid-based BJM3DP can be completed through the thermal treatments of green bodies, where the debinding and sintering result in the merging of metal particles and thus provides an abrupt enhancement in the mechanical strengths. In order to minimize the rapid shrinkage and maintain the structural integrity during the initial debinding process, the optimization of debinding temperature and duration is required to remove an appropriate amount of chelation bridges at mild rate. Since the citric acid thermally decomposes above $175^{\circ} \mathrm{C}$, which is far lower than that of other water-soluble polymeric binders such as PVP, it is necessary to choose lower debinding temperature. A fine adjustments and optimizations are out-of-scope for this work and would require further study, but our choice of conditions $\left(350^{\circ} \mathrm{C}\right.$ for $3 \mathrm{~h}$ ) did not sacrifice the structural integrity. This work also demonstrated that, the chelation chemistry of citric acid observed in $\mathrm{Al}$ could be expanded to various metals such as $\mathrm{Cu}, \mathrm{Fe}$, and $\mathrm{Ti}-\mathrm{Al} 6-4 \mathrm{~V}$ alloy. Based on these aspects, the proposed facile approach of using environmentally friendly chelators is expected be a cornerstone for promoting the development of the highly approachable, low-cost, and safe consumer-level desktop metal 3D printing systems.

\footnotetext{
Methods

Materials. The four chelator powders were prepared by grinding sodium ascorbate ( $\geq 99 \%$, Sigma-Aldrich), sodium succinate ( $\geq 99 \%$, Sigma-Aldrich), sodium tartrate ( $\geq 99 \%$, Sigma-Aldrich), and sodium citrate ( $\geq 99 \%$, Sigma-Aldrich). Al powder was purchased from Henan Yuanyang Powder Technology Co., Ltd (FLPN10 for $10 \mu \mathrm{m}$ ),
}

from Korea Powder Co.,(CAS\#: 7429-90-5 for $75 \mu \mathrm{m}$ powders) and from Changsung $(\leq 40 \mathrm{mesh}, 355 \mu \mathrm{m}$ ). The size distribution was confirmed by using ISO 13320 laser diffraction method (Beckman Coulter LS-13-320), as presented in Supplementary Fig. 16. Then, each chelator powder was uniformly mixed at a concentration of $20 \%(\mathrm{w} /$ w) with $\mathrm{Al}$ powder ( $\leq 40$ mesh, Changsung) and then sieved through a mesh. Sodium chloride ( $\geq 99 \%$, Sigma-Aldrich) with a concentration of $5 \%(w / w)$ was used as an additive. The preparation procedure of the other three metal powders $(\mathrm{Cu}(\leq 40$ mesh, Sigma-Aldrich), Fe ( $\leq 325$ mesh, Duksan), and Ti-6Al-4 V ( $\leq 325$ mesh, Grade 5, Korea Powder)) was the same as that of the metal chelator mixture.

BJM3DP process. The desktop printer for BJM3DP was assembled using a fusion deposition modeling 3D printer kit (Geeetech I3 Pro, Shenzhen Getech Co., Ltd.). An acrylic gantry box add-on set (Colorpod, Spitstec, Netherlands) was mounted on the assembled metal 3D printer. BJM3DP was performed in an environment in which room temperature $\left(\sim 25^{\circ} \mathrm{C}\right)$ and $20 \%$ relative humidity were maintained. An inkjet cartridge (HP45, Hewlett-Packard) was filled with $30 \mathrm{~mL}$ of DI water. The printing speeds was fixed at $2000 \mathrm{~mm} \mathrm{~min}^{-1}$. The temperature of both the builder platform and the inkjet nozzle was maintained at $70^{\circ} \mathrm{C}$ to control the evaporation rate of water during the $3 \mathrm{D}$ printing process. The process parameters are summarized in the Supplementary Table 2 . After the $3 \mathrm{D}$ printing process, the printed object was humidified by exposing it to a humidifier spraying water at a rate of $35 \mathrm{~mL} \mathrm{~h}^{-1}$ in a cylindrical chamber for $30 \mathrm{~min}$. Subsequently, the printed object was thermally sintered in a tube furnace (LHA-12/300, Lenton) under vacuum ( 0.03 torr). The heat treatment profiles are shown in Supplementary Fig. 20.3 cycles of the following heat treatment profile are conducted: (Debinding) Heating from RT to $350^{\circ} \mathrm{C}$ by $10^{\circ} \mathrm{C} / \mathrm{min}$ followed by $350^{\circ} \mathrm{C}$ treatment for $3 \mathrm{~h}$. (Sintering) Heating from 350 to $620^{\circ} \mathrm{C}$ by $10^{\circ} \mathrm{C} / \mathrm{min}$ followed by $620^{\circ} \mathrm{C}$ treatment for $15 \mathrm{~h}$. (Cooling) Cooling from $620^{\circ} \mathrm{C}$ to RT by $-10^{\circ} \mathrm{C} / \mathrm{min}$.

Characterization. The formation of a metal-chelate complex between the $\mathrm{Al}$ particles in the 3D-printed objects was confirmed by FT-IR spectroscopy (VERTEX 70, Bruker Corporation, Germany) and XPS analysis (ESCALAB 250Xi, Thermo-Scientific, USA) The 3D-printed objects were visualized by SEM (JEOL-7800F, JEOL, Ltd., Japan). For compression tests, objects were 3D-printed according to the ASTM E9 standard. Compression tests were performed using a universal testing machine (QC-506M2F, Cometech) with a compression rate of $8 \mathrm{~mm} \mathrm{~s}^{-1}$. Data are presented with mean values \pm standard deviations (s.d.). The bulk density and porosity of printed objects were acquired by using $3 \mathrm{D}$ computed tomography ( $\mu$ CT, Nikon XTH 320) with the voxel size of $1 \mu \mathrm{m}$ at X-ray beam energy of $210 \mathrm{kV}$. Voxel analysis and 3D visualization were performed by using VGSTUDIO MAX (Volume Graphics Pte. Ltd). The interparticle porosity of the 3D-printed objects was measured by mercury intrusion porosimetry (PM33GT, Quantachrome).

\section{Data availability}

All data generated or analyzed during this study are included in this published article (and its Supplementary Information files).

Received: 8 March 2021; Accepted: 29 November 2021; Published online: 07 March 2022

\section{References}

1. Kim, S. H. et al. Precisely printable and biocompatible silk fibroin bioink for digital light processing 3D printing. Nat. Commun. 9, 1620 (2018)

2. Ge, Q. et al. 3D printing of highly stretchable hydrogel with diverse UV curable polymers. Sci. Adv. 7, eaba4261 (2021).

3. Giachini, P. A. G. S. et al. Additive manufacturing of cellulose-based materials with continuous, multidirectional stiffness gradients. Sci. Adv. 6, eaay0929 (2020).

4. Darkes-Burkey, C. \& Shepherd, R. F. High-resolution 3D printing in seconds. Nature 588, 594-595 (2020)

5. Regehly, M. et al. Xolography for linear volumetric 3D printing. Nature $\mathbf{5 8 8}$ 620-624 (2020).

6. Deore, B. et al. Direct printing of functional 3D objects using polymerizationinduced phase separation. Nat. Commun. 12, 55 (2021).

7. Kenel, C., Casati, N. P. M. \& Dunand, D. C. 3D ink-extrusion additive manufacturing of CoCrFeNi high-entropy alloy micro-lattices. Nat. Commun 10, 904 (2019).

8. Zhang, D. et al. Additive manufacturing of ultrafine-grained high-strength titanium alloys. Nature 576, 91-95 (2019).

9. Pollock, T. M. Alloy design for aircraft engines. Nat. Mater. 15, 809-815 (2016)

10. Daly, A. C., Davidson, M. D. \& Burdick, J. A. 3D bioprinting of high celldensity heterogeneous tissue models through spheroid fusion within selfhealing hydrogels. Nat. Commun. 12, 753 (2021).

11. Liang, K., Carmone, S., Brambilla, D. \& Leroux, J.-C. 3D printing of a wearable personalized oral delivery device: A first-in-human study. Sci. Adv. 4, eaat2544 (2018). 
12. Robinson, S. S. et al. Patient-specific design of a soft occluder for the left atrial appendage. Nat. Biomed. Eng. 2, 8-16 (2018).

13. Ho, D. H. et al. 3D-printed sugar scaffold for high-precision and highly sensitive active and passive wearable sensors. Adv. Sci. 7, 1902521 (2020)

14. Gervasoni, S. et al. CANDYBOTS: A new generation of 3D-printed sugarbased transient small-scale robots. Adv. Mater. 32, 2005652 (2020).

15. Jakus, A. E., Taylor, S. L., Geisendorfer, N. R., Dunand, D. C. \& Shah, R. N. Metallic architectures from 3D-printed powder-based liquid inks. Adv. Funct. Mater. 25, 6985-6995 (2015)

16. Taylor, S. L., Jakus, A. E., Shah, R. N. \& Dunand, D. C. Iron and nickel cellular structures by sintering of 3D-printed oxide or metallic particle inks. Adv. Eng. Mater. 19, 1600365 (2017).

17. Reiser, A. et al. Multi-metal electrohydrodynamic redox 3D printing at the submicron scale. Nat. Commun. 10, 1853 (2019).

18. Vyatskikh, A. et al. Additive manufacturing of 3D nano-architected metals. Nat. Commun. 9, 593 (2018)

19. Gustmann, T. et al. Influence of processing parameters on the fabrication of a $\mathrm{Cu}-\mathrm{Al}-\mathrm{Ni}-\mathrm{Mn}$ shape-memory alloy by selective laser melting. Addit. Manuf. 11, 23-31 (2016).

20. Zhang, B. C., Dembinski, L. \& Coddet, C. The study of the laser parameters and environment variables effect on mechanical properties of high compact parts elaborated by selective laser melting 316L powder. Mater. Sci. Eng. A 584, 21-31 (2013).

21. Karlsson, J., Snis, A., Engqvist, H. \& Lausmaa, J. Characterization and comparison of materials produced by electron beam melting (EBM) of two different Ti-6Al-4V powder fractions. J. Mater. Process. Technol. 213, 2109-2118 (2013).

22. Gokuldoss, P. K., Kolla, S. \& Eckert, J. Additive manufacturing processes: selective laser melting, electron beam melting and binder jetting-selection guidelines. Materials 10, 672 (2017).

23. Sachs, E., Cima, M. \& Cornie, J. Three-dimensional printing: Rapid tooling and prototypes directly from a CAD model. CIRP Ann. Manuf. Technol. 39, 201-204 (1990).

24. Mostafaei, A. et al. Binder jet 3D printing-process parameters, materials, properties, modeling, and challenges. Prog. Mater. Sci. 24, 100707 (2020).

25. ASTM. F2792-12a. Standard Terminology for Additive Manufacturing Technologies (ASTM International, 2012).

26. Ni, J. et al. Three-dimensional printing of metals for biomedical applications. Mater. Today Bio 3, 100024 (2019).

27. Bai, Y. \& Williams, C. B. An exploration of binder jetting of copper. Rapid Prototyp. J. 21, 177-185 (2015).

28. Gilmer, D. et al. An in-situ crosslinking binder for binder jet additive manufacturing. Addit. Manuf. 35, 101341 (2020).

29. Levy, A., Miriyev, A., Elliott, A., Babu, S. S. \& Frage, N. Additive manufacturing of complex-shaped graded TiC/steel composites. Mater. Des. 118, 198-203 (2017).

30. Michaels, S., Sachs, E. M. \& Cima, M. J. Metal parts generation by three dimensional printing. In 1992 International Solid Freeform Fabrication Symposium (Laboratory for Freeform Fabrication and University of Texas at Austin, 1992).

31. Hughes, K., Meek, M. E., Walker, M., Turner, L. \& Moir, D. 2-Butoxyethanol: Hazard characterization and exposure-response analysis. J. Environ. Sci. Health, Part C: Toxicol. Carcinog. 19, 77-104 (2001).

32. Harreus, A. L. et al. 2-Pyrrolidone. Ullmann's Encyclopedia of Industrial Chemistry (Wiley, 2011).

33. Toxic pollutants (40 CFR 401.15), Title 40 - Protection of Environment (AE 2.106/3:40/), Code of Federal Regulations (2011).

34. Schafer, E. W., Bowles, W. A. \& Hurlbut, J. The acute oral toxicity, repellency, and hazard potential of 998 chemicals to one or more species of wild and domestic birds. Arch. Environ. Contam. Toxicol. 12, 355-382 (1983).

35. Rabinskiy, L., Ripetsky, A., Sitnikov, S., Solyaev, Y. \& Kahramanov, R. Fabrication of porous silicon nitride ceramics using binder jetting technology. IOP Conf. Ser.: Mater. Sci. Eng. 140, 012023 (2016).

36. El-Ghannam, A., Cunningham, L. Jr., Pienkowski, D. \& Hart, A. Bone engineering of the rabbit ulna. J. Oral. Maxillofac. Surg. 65, 1495-1502 (2007).

37. Zhou, Z., Lennon, A., Buchanan, F., McCarthy, H. O. \& Dunne, N. Binder jetting additive manufacturing of hydroxyapatite powders: Effects of adhesives on geometrical accuracy and green compressive strength. Addit. Manuf. 36, 101645 (2020).

38. Lv, X., Ye, F., Cheng, L., Fan, S. \& Liu, Y. Binder jetting of ceramics: Powders, binders, printing parameters, equipment, and post-treatment. Ceram. Int. 45, 12609-12624 (2019).

39. Afshar-Mohajer, N., Wu, C.-Y., Ladun, T., Rajon, D. A. \& Huang, Y. Characterization of particulate matters and total VOC emissions from a binder jetting 3D printer. Build. Environ. 93, 293-301 (2015).

40. Zontek, T. L., Ogle, B. R., Jankovic, J. T. \& Hollenbeck, S. M. An exposure assessment of desktop 3D printing. J. Chem. Health Saf. 24, 15-25 (2017).

41. Chen, R. et al. Exposure, assessment and health hazards of particulate matter in metal additive manufacturing: A review. Chemosphere 259, 127452 (2020).
42. Maleksaeedi, S., Meenashisundaram, G. K., Lu, S., Salehi, M. \& Jun, W. Hybrid binder to mitigate feed powder segregation in the inkjet 3D printing of titanium metal parts. Metals 8, 322 (2018).

43. Keçebaş, A. \& Kayfeci, M. Chapter 1 - Hydrogen Properties. Solar Hydrogen Production (Academic Press, 2019).

44. Asemave, K. Greener chelators for recovery of metals and other applications Org. Medicinal Chem. Ij. 6, 555694 (2018).

45. Sekhara Varma, T. N. \& Ramakrishnan, C. V. Biosynthesis of citric acid in citrus fruits. Nature 178, 1358-1359 (1956)

46. Fraga, A. K. et al. Synthesis and characterization of aluminum citrate compounds and evaluation of their influence on the formation of hydrogels based on polyacrylamide. Iran. Polym. J. 29, 649-657 (2020).

47. Papageorgiou, S. K. et al. Metal-carboxylate interactions in metal-alginate complexes studied with FTIR spectroscopy. Carbohydr. Res. 345, 469-473 (2010).

48. Nakamoto, K. in Handbook of Vibrational Spectroscopy (Wiley, 2006).

49. Tajmirriahi, H. A. Coordination chemistry of vitamin-C. Part III. Interaction of Lascorbic-acid with $\mathrm{Al}(\mathrm{III}), \mathrm{La}(\mathrm{III})$, and $\mathrm{Pb}(\mathrm{II})$ ions - Evidence for metal chelate formation in the solid and aqueous-solution. J. Inorg. Biochem. 44, 39-45 (1991).

50. Sherwood, P. M. A. Introduction to studies of aluminum and its compounds by XPS. Surf. Sci. Spectra 5, 1-3 (1998).

51. Wysocka, J., Krakowiak, S. \& Ryl, J. Evaluation of citric acid corrosion inhibition efficiency and passivation kinetics for aluminium alloys in alkaline media by means of dynamic impedance monitoring. Electrochim. Acta 258, 1463-1475 (2017)

52. Li, W., Cochell, T. \& Manthiram, A. Activation of aluminum as an effective reducing agent by pitting corrosion for wet-chemical synthesis. Sci. Rep. 3, 1229 (2013)

53. Li, M., Du, W., Elwany, A., Pei, Z. \& Ma, C. Metal binder jetting additive manufacturing: A literature review. J. Manuf. Sci. Eng. 142, 090801 (2020)

54. Ziaee, M. \& Crane, N. B. Binder jetting: A review of process, materials, and methods. Addit. Manuf. 28, 781-801 (2019).

55. Bai, Y., Wagner, G. \& Williams, C. B. Effect of particle size distribution on powder packing and sintering in binder jetting additive manufacturing of metals. J. Manuf. Sci. Eng. 139, 081019 (2017).

56. Du, W. et al. Binder jetting additive manufacturing: Effect of particle size distribution on density. J. Manuf. Sci. Eng. 143, 091002 (2021).

57. Kunchala, P. \& Kappagantula, K. 3D printing high density ceramics using binder jetting with nanoparticle densifiers. Mater. Des. 155, 443-450 (2018)

58. Chai, W. et al. The printability of three water based polymeric binders and their effects on the properties of 3D printed hydroxyapatite bone scaffold. Ceram. Int. 46, 6663-6671 (2020).

59. Tang, Y., Huang, Z., Yang, J. \& Xie, Y. Enhancing the capillary force of binderjetting printing Ti6Al4V and mechanical properties under high temperature sintering by mixing fine powder. Metals 10, 1354 (2020).

60. Miyanaji, H. et al. Binder jetting additive manufacturing of copper foam structures. Addit. Manuf. 32, 100960 (2020).

61. Williams, C. B., Cochran, J. K. \& Rosen, D. W. Additive manufacturing of metallic cellular materials via three-dimensional printing. Int. J. Adv. Manuf. Technol. 53, 231-239 (2011).

62. Meenashisundaram, G. K. et al. Fabrication of $\mathrm{Ti}+\mathrm{Mg}$ composites by threedimensional printing of porous $\mathrm{Ti}$ and subsequent pressureless infiltration of biodegradable Mg. Mater. Sci. Eng. C. 108, 110478 (2020).

\section{Acknowledgements}

J.H.C. was supported by the Creative Materials Discovery Program (2019M3D1A1078299) through the National Research Foundation (NRF) of Korea funded by the Ministry of Science and ICT, Korea, the Basic Science Program through the NRF of Korea funded by the Ministry of Science and ICT, Korea (2020R1A4A2002806), and the Korea Medical Device Development Fund grant funded by the Korea government (the Ministry of Science and ICT, the Ministry of Trade, Industry and Energy, the Ministry of Health \& Welfare, the Ministry of Food and Drug Safety) (Project Number: KMDF_PR_20200901_0093, 9991006766). J.H.C. was partially supported by the Yonsei Signature Research Cluster Program of 2021 (2021-22-0004).

\section{Author contributions}

J.H.C. conceived the concept, designed all the experiments, and supervised the work. S.Y.C. and D.H.H. carried out most of the experimental work and data analysis. Y.Y.C. assisted the data analysis with all other authors. S.Li, S.Le, and J.W.S. performed the mechanical property analysis of 3D printed object. S.B.J. led and supervised the whole revision process, including designing experiments, reorganizing the rationale, and editing the manuscript. All authors discussed the progress of research and contributed to editing the manuscript.

\section{Competing interests}

The authors declare no competing interests. 


\section{Additional information}

Supplementary information The online version contains supplementary material available at https://doi.org/10.1038/s41467-021-27730-6.

Correspondence and requests for materials should be addressed to Sae Byeok Jo or Jeong Ho Cho.

Peer review information Nature Communications thanks the anonymous reviewers for their contribution to the peer review of this work. Peer reviewer reports are available.

Reprints and permission information is available at http://www.nature.com/reprints

Publisher's note Springer Nature remains neutral with regard to jurisdictional claims in published maps and institutional affiliations. (c) (1) Open Access This article is licensed under a Creative Commons Attribution 4.0 International License, which permits use, sharing, adaptation, distribution and reproduction in any medium or format, as long as you give appropriate credit to the original author(s) and the source, provide a link to the Creative Commons license, and indicate if changes were made. The images or other third party material in this article are included in the article's Creative Commons license, unless indicated otherwise in a credit line to the material. If material is not included in the article's Creative Commons license and your intended use is not permitted by statutory regulation or exceeds the permitted use, you will need to obtain permission directly from the copyright holder. To view a copy of this license, visit http://creativecommons.org/ licenses/by/4.0/.

(C) The Author(s) 2022 